\title{
An Important Approach for Control of Enterohaemorrhagic Escherichia coli by Identification of Contaminating Sources in Beef Production Line
}

\author{
Anu P. Joseph ${ }^{1 *}$, C. Latha ${ }^{1}$, K. Vinodkumar ${ }^{2}$, V.K. Vinod ${ }^{1}$ and T. Sathu ${ }^{3}$ \\ ${ }^{1}$ Department of Veterinary Public Health, ${ }^{2}$ Department of Veterinary Epidemiology and \\ Preventive Medicine, ${ }^{3}$ Department of Livestock Product Technology, Kerala Veterinary and \\ Animal Sciences University, India \\ *Corresponding author
}

\section{A B S T R A C T}

\begin{tabular}{|l|}
\hline Ke y w o r d s \\
Beef production line, \\
Critical control point, \\
Enterohaemorrhagic $E$. \\
coli, Food borne \\
pathogen, Slaughter \\
house
\end{tabular}

\section{Introduction}

The growing concern about foodborne infection has resulted in more focus on the preventive measures nowadays. Contamination of food can occur at any stage of production process till it reaches the consumer. Among the major food borne pathogens, Enterohaemorrhagic Escherichia coli (EHEC) is one of the most important bacteria when beef production line is considered. The strains of EHEC are unusually virulent because of its low infectious dose, severe consequences of

\begin{abstract}
Lack of an efficient antibiotic treatment for Enterohaemorrhagic Escherichia coli (EHEC) infection has resulted in more focus on the preventive measures against this foodborne pathogen. To determine the contaminating sources of EHEC in beef production lines, 1056 samples including dung, hide, operator hand wash, knife wash, surface swabs, beef carcass swabs, water, air and beef samples were collected from four different slaughter houses situated in Kerala, India. An overall occurrence of $7.39 \%$ of EHEC was found from slaughter houses and all the samples except air was found as contaminating sources. The study reveals a high prevalence of EHEC in slaughter houses failing to follow hygienic measures. This necessitates the urgent need of certification of slaughter houses and establishment of control measures at these identified points to prevent EHEC epidemics.
\end{abstract}

infection like haemorrhagic colitis and hemolytic uremic syndrome in humans, low acid tolerance, biofilm formation and antibiotic induced toxin release (Wells et al., 1983; Tarr et al., 1990; Benjamin and Datta, 1995; Hood and Zottola, 1997; Tuttle et al., 1999; Bielaszewska et al., 2012). Humans generally get infection by direct contact with carriers, their faeces, and contaminated soil and water. Also ingestion of contaminated beef products, milk, vegetables and fruits results in infection. Cattle, which are considered as the main reservoir for EHEC, are capable of shedding these pathogens 
asymptomatically in their faeces (Chapman et al., 1993). The contaminating sources of EHEC may not be the same for different slaughter houses. So it becomes necessary to identify the sources through which EHEC gets entry into the beef production line considering individual slaughter houses to determine critical control points $(\mathrm{CCP})$ for this pathogen.

In the World, India is the leading country in cattle population as well as beef export. The foreign export from this country accounts for 48 per cent of the total beef production from India (USDA, 2015). Considering the contribution of India to the global beef industry, carrier status of ruminants for EHEC and the serious impact of EHEC infection in humans, the present study was carried out to determine the sources of contamination and CCPs of this pathogen in beef production facilities located in one of the Indian state Kerala, were cattle slaughter is allowed under the state law.

\section{Materials and Methods}

A total of 1056 samples comprising of dung, hide, knife wash, operator hand wash, surface swabs (floor and tabletops), water, air and beef were collected from four different slaughter houses $\mathrm{SH} 1, \mathrm{SH} 2, \mathrm{SH} 3$ and $\mathrm{SH} 4$ situated in Kerala, India. All the samples were collected during a period of 15 months from February 2014 to May 2015.

Approximately $100 \mathrm{~g}$ of dung samples were collected in sterile bottles from 134 cattle presented to slaughter. For collecting samples of hide $(n=113)$, surface $(n=93)$ and beef carcass $(n=151)$, swab contact method was used. Swab samples were taken by swabbing an area of $500 \mathrm{~cm}^{2}$ each of hide surface and beef carcass and $100 \mathrm{~cm}^{2}$ area of surface samples. These swabs were transferred to 25 $\mathrm{ml}$ of peptone water immediately after collection. Knife $(n=97)$ and hand washings $(n=127)$ were collected by washing the knife or operator hand in $100 \mathrm{ml}$ of 0.1 per cent peptone water in sterile polythene bags. Water $(n=72)$ for bacteriological examination were also collected following standard procedures (Indian Standards, 1978). Direct exposure method was used for the estimation of bacterial counts in the 69 air samples of four different slaughter houses. Two hundred fresh beef samples of $100 \mathrm{~g}$ each were collected from slaughter houses in sterile polythene bags. The aseptically collected samples were brought to the laboratory under refrigerated condition and processed within $24 \mathrm{~h}$ for the analysis.

A 25 gram portion of each sample was aseptically transferred to $225 \mathrm{ml}$ of Trypticase Soya Broth (TSB) (HiMedia, India) in a stomacher bag. It was then homogenized in a stomacher for $180 \mathrm{~s}$. For swabs, $25 \mathrm{ml}$ of peptone water with swabs formed the initial test sample. Isolation and identification of Enterohaemorrhagic E. coli from collected samples were carried out by pre-enrichment and selective enrichment followed by selective plating as described by Meng et al., (2001) with slight modification. For pre-enrichment, homogenised samples in TSB were incubated at $37{ }^{0} \mathrm{C}$ for $24 \mathrm{~h}$. From the pre- enriched sample, $1 \mathrm{ml}$ was transferred to $9 \mathrm{ml}$ of selective broth (EC broth) (HiMedia, India) and incubated at $37{ }^{\circ} \mathrm{C}$ for $24 \mathrm{~h}$. Samples in EC broth were selectively plated on to Eosin Methylene Blue (EMB) agar (HiMedia, India) and incubated at $37{ }^{0} \mathrm{C}$ for $24 \mathrm{~h}$. Three colonies with characteristics of $E$. coli were selected from EMB plate and streaked onto Cefixime Tellurite- Sorbitol Mac Conkey (CT- SMAC) agar plates (HiMedia, India). The plates were incubated at $37{ }^{\circ} \mathrm{C}$ for $18-24$ $\mathrm{h}$. The isolates were further confirmed by plating onto 4-methylumbelliferyl-beta-Dglucuronide (MUG EC) agar (Fujisawa et al., 2000) (HiMedia, India). The suspected colonies of Enterohaemorrhagic E. coli were 
subjected to various tests and identified based on the cultural, morphological and biochemical characteristics (Barrow and Feltham, 1993). The pathogenicity of the EHEC isolates was also tested by Congo red binding assay (Rajil et al., 2003). The data obtained were subjected to statistical analysis by using SPSS version 21.0 (Snedecor and Cochran, 1994).

\section{Results and Discussion}

The EHEC on CT-SMAC agar plate appeared as 1- $2 \mathrm{~mm}$ diameter non- sorbitol fermenting transparent neutral grey colonies with smoky centre (Fig. 1). These EHEC colonies were non-fluorescent in MUG EC agar under UV illumination (Fig. 2). All the positive isolates from beef processing line were found to be pathogenic by Congo red binding assay.

The highest contamination of EHEC in slaughter houses were found in the samples of beef (20.50 per cent). Dung of the animal showed 7.46 per cent and operator hands showed 7.09 per cent occurrence of EHEC. The contamination in processing surface, knife, beef carcass, hides and water source were $5.38,4.12,3.31,2.65$ and 1.39 per cent respectively. Air was not found as a source of contamination in any of the slaughter houses. The overall occurrence of EHEC in slaughter houses was 7.39 per cent (Table 1).

On statistical analysis by Pearson Chi-Square test, Enterohaemorrhagic E. coli contamination of beef was found to be significantly different $(\mathrm{p}<0.05)$ from all other sources whereas between other sources in the slaughter house, no statistical difference was found. In SH1, between the positive sources no statistical difference $(p<0.05)$ was observed. The occurrence of EHEC in dung and beef samples of $\mathrm{SH} 2$ showed no significant difference $(\mathrm{p}<0.05)$ to each other.
Also the occurrence in dung was statistically non- significant with the operator hand wash and knife wash. The occurrence of EHEC in operator hands and knife were non-significant $(\mathrm{p}<0.05)$ with its occurrence in hide and surface swabs. All the positive samples except beef samples in SH4 were statistically nonsignificant $(p<0.05)$ to each other.

In SH1, 2.5 per cent of the beef carcass and 2.94 per cent of the beef were found to be contaminated with EHEC. The major source of contamination was found to be the floor surface where processing was carried out. The hide of the animal was found as a contaminating source in 1.82 per cent of the animals. The statistical analysis showed no significant difference $(\mathrm{p}<0.05)$ between the occurrence of EHEC in hide, floor surface and beef carcass. So it can be inferred that the hide of the animal, floor surface and beef carcass as the critical points of contamination in this slaughter house. So the slaughter operations, dehiding and evisceration can be considered as the critical control points (CCP1) where all the points of contamination can be effectively controlled. It was observed that in SH1, all the processes from bleeding to carcass splitting were carried out on the floor surface. During bleeding, the animal was falling down on the ground and the dirt and manure on the hide of the animal was found contaminating the floor. The EHEC organisms might have transferred to beef carcass and beef when the same floor was used for dehiding and splitting of carcass. There was also a practice of keeping the eviscerated contents of animal near to the beef carcass. Even though after finishing each slaughter the carcass was moved from the floor, the tripe of the animal was remaining there itself. So there is a possibility of contamination of carcass by the leaky digestive tract contents of the slaughtered animal. 
Table.1 Overall occurrence of EHEC in slaughter houses

\begin{tabular}{|c|c|c|c|c|c|c|c|c|c|c|c|}
\hline \multirow{3}{*}{$\begin{array}{l}\text { Sl } \\
\text { no. }\end{array}$} & \multirow[t]{3}{*}{ Sources } & \multicolumn{8}{|c|}{ EHEC positive samples (\%) } & \multicolumn{2}{|c|}{ Overall } \\
\hline & & \multicolumn{2}{|c|}{ SH1 } & \multicolumn{2}{|c|}{$\mathrm{SH} 2$} & \multicolumn{2}{|c|}{ SH3 } & \multicolumn{2}{|c|}{ SH4 } & \multirow[t]{2}{*}{$\mathrm{SC}$} & \multirow[t]{2}{*}{ PI } \\
\hline & & $\mathrm{SC}$ & PI & $\mathrm{SC}$ & PI & $\mathrm{SC}$ & PI & $\mathrm{SC}$ & PI & & \\
\hline 1. & Dung & 52 & 0 & 30 & $10^{\mathrm{ab}}$ & 52 & 0 & NS & NS & 134 & $10^{\mathrm{a}}$ \\
\hline 2. & Hide & 55 & $1^{\mathrm{a}}$ & 32 & $1^{\mathrm{cd}}$ & 26 & 1 & NS & NS & 113 & $3^{a}$ \\
\hline 3. & Operator hand wash & 30 & 0 & 28 & $4^{\mathrm{ac}}$ & 32 & 0 & 37 & $5^{c}$ & 127 & $9^{a}$ \\
\hline 4. & Knife wash & 20 & 0 & 24 & $3^{\mathrm{ac}}$ & 35 & 0 & 18 & $1^{\mathrm{c}}$ & 97 & $4^{a}$ \\
\hline 5. & Beef carcass swab & 40 & $1^{\mathrm{a}}$ & 36 & 0 & 49 & 0 & 26 & $4^{b c}$ & 151 & $5^{a}$ \\
\hline 6. & Surface & 15 & $1^{\mathrm{a}}$ & 31 & $3^{\mathrm{cd}}$ & 24 & 0 & 23 & $1^{b c}$ & 93 & $5^{a}$ \\
\hline 7. & Water & 14 & 0 & 24 & 0 & 15 & 0 & 19 & $1^{\mathrm{c}}$ & 72 & $1^{\mathrm{a}}$ \\
\hline 8. & Air & 16 & 0 & 18 & 0 & 14 & 0 & 21 & 0 & 69 & 0 \\
\hline 9. & Beef & 68 & $2^{a}$ & 39 & $17^{\mathrm{b}}$ & 58 & 0 & 35 & $22^{\mathrm{a}}$ & 200 & $41^{b}$ \\
\hline & Total & 310 & 5 & 262 & 38 & 305 & 1 & 179 & 34 & 1056 & 78 \\
\hline
\end{tabular}

Figures bearing same superscripts in a column do not differ significantly $(\mathrm{p}<0.05)$

SC- Samples collected, PI- Positive isolates, NS- No samples

Fig.1 Enterohaemorrhagic E. coli colonies on CT-SMAC agar plate

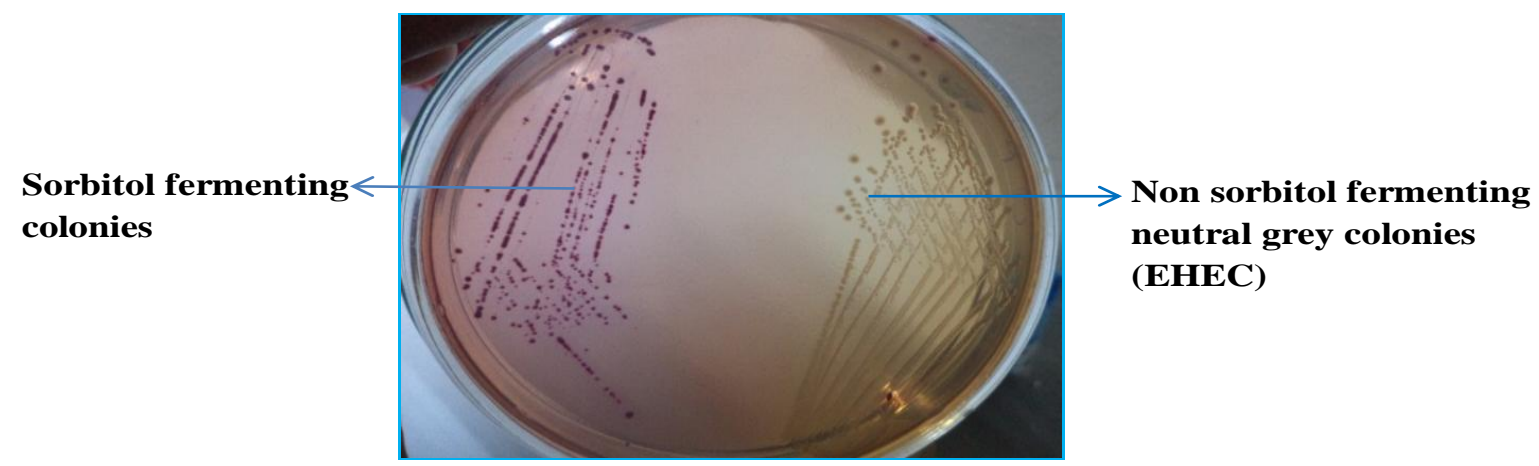

Fig.2 Enterohaemorrhagic E. coli colonies on MUG-EC agar plate

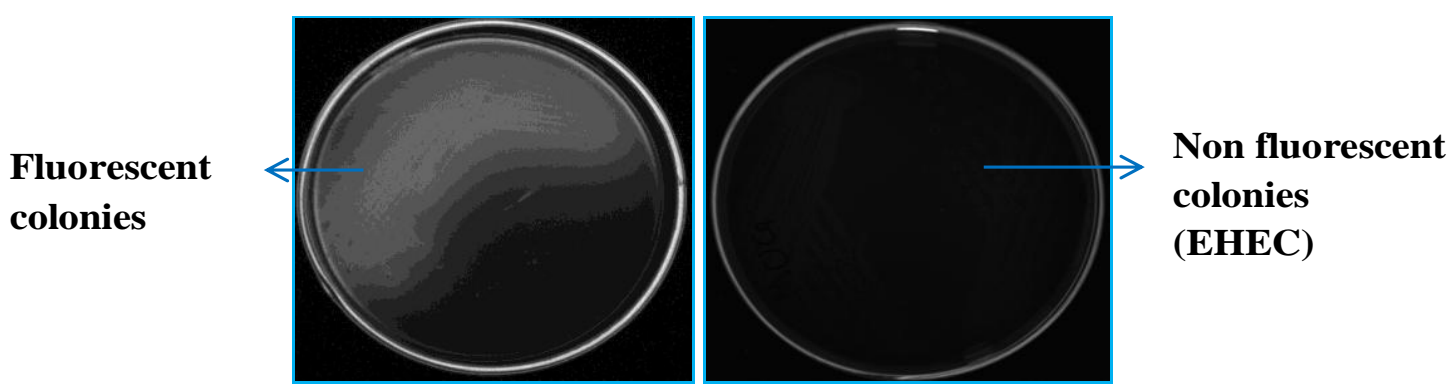


Fig.3 Contamination sources of EHEC in beef production line

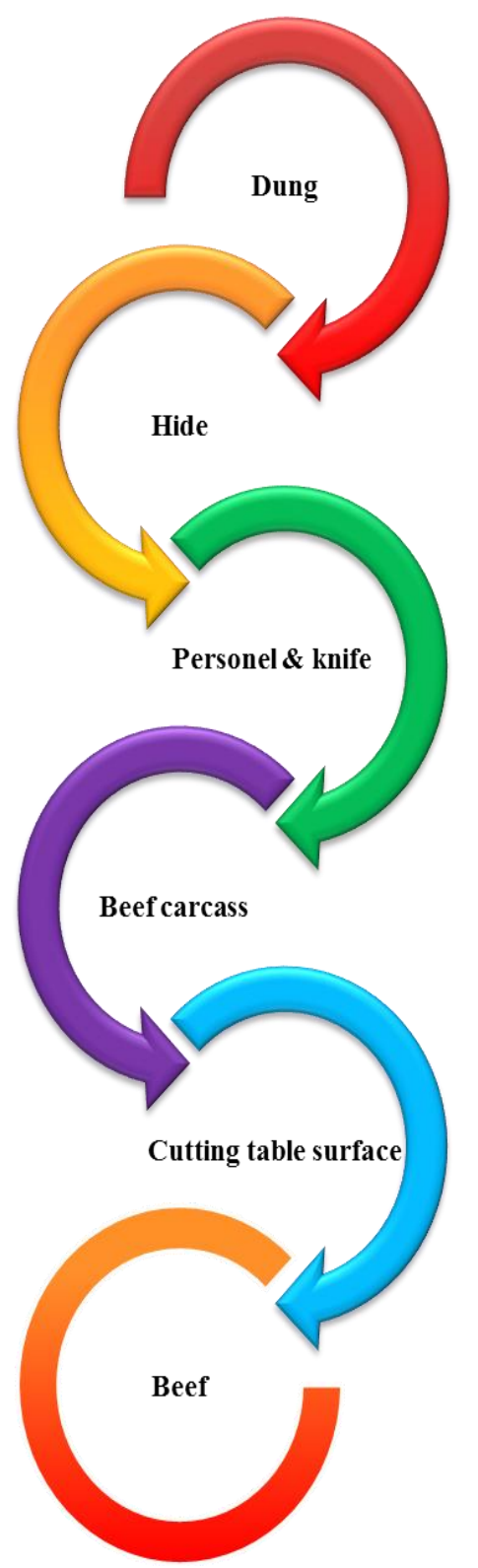


Fig.4 Critical control points of EHEC in beef production line

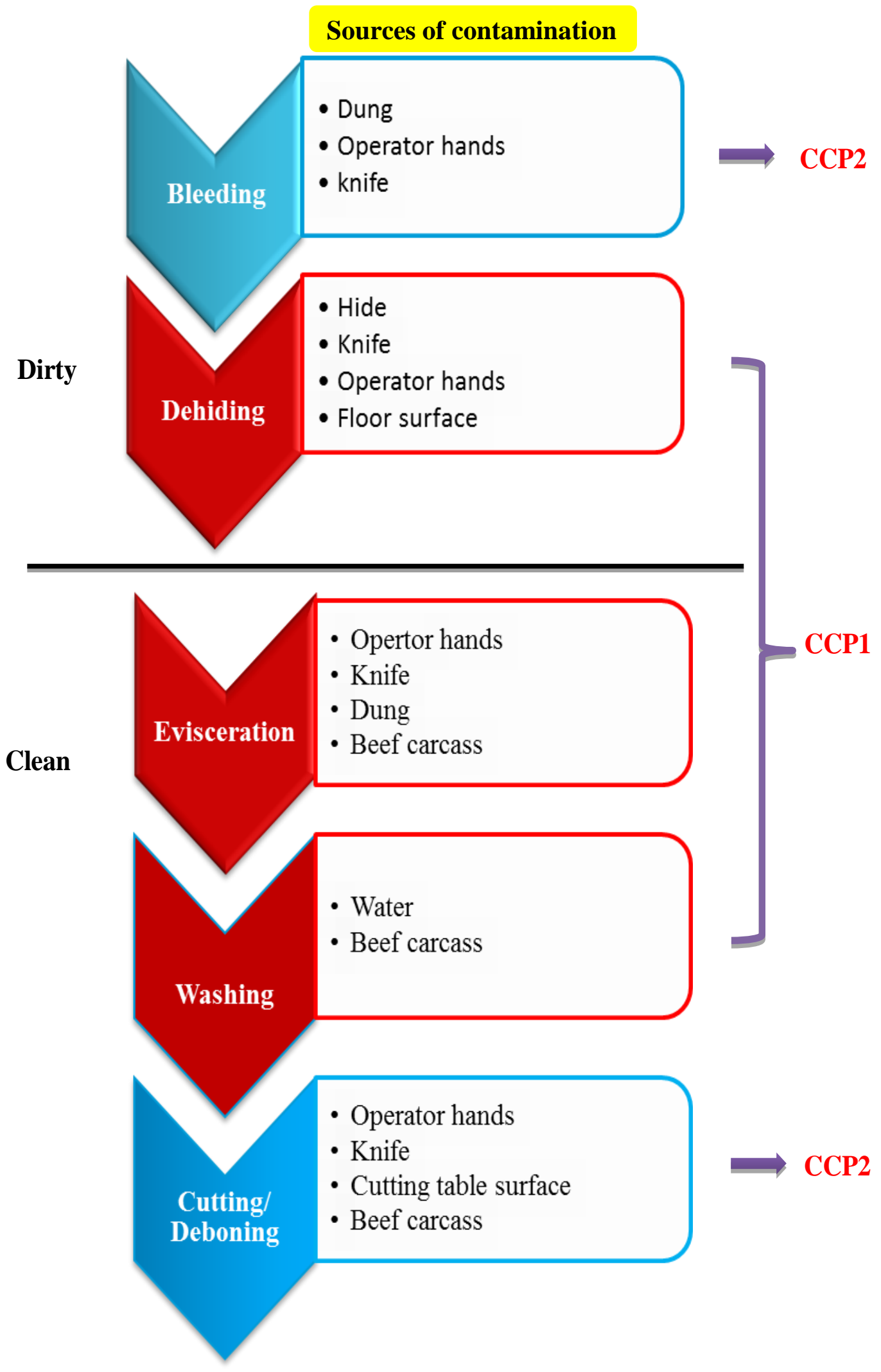


A high occurrence of EHEC organisms was found in beef samples of $\mathrm{SH} 2$. The highest possible source of contamination was the dung of the animal. The pathogen can survive in dung for more than 40 days under a wide range of temperature (Wang et al., 1996). So there is a chance of persistence of EHEC in slaughter house environment following an ineffective cleaning and disinfection, which can remain as a source of contamination to the subsequent lot. Since there was no significant difference $(\mathrm{p}<0.05)$ between the occurrence of EHEC in dung and beef, it can be hypothesised that the dung was the main source which has resulted in the high occurrence of EHEC organisms in beef. The other critical points of contamination identified in $\mathrm{SH} 2$ were hide, operator hands, knife and floor surface. Statistical analysis of these critical points of contamination revealed, dung, hide and floor surface as the major sources of contamination to operator hands and cutting knife which inturn has resulted in the contamination of beef with EHEC organisms. In this slaughter house there was no overhead rail system and all the slaughter processes were taking place on the floor. During bleeding, the animal was found to be struggling and it was voiding dung to the floor surface. When the animal fells over the dung material, the hide was contaminated with dung. At the bleeding stage the blood which was found flowing through the ground spreads these dung material to a large area and it was observed that the blood when coagulated, the dung removal from the surfaces becoming difficult and it acts as a source of cross contamination. From the contaminated hide, EHEC organisms might have transferred to the operator hands. The occurrence of EHEC organisms in knife may be due to the contamination of knife during bleeding and hide removal. There is another possibility of getting EHEC in beef i.e., an accidental contamination of carcass at evisceration stage. From the above findings, dehiding stage can be considered as the CCP1 and bleeding and evisceration stage as CCP2. At CCP1 the major sources of contamination were dung, hide, operator hand, knife and floor surface.

In SH3 (only buffalo slaughter was there), low occurrence of Enterohaemorrhagic E. coli was noticed. The only one EHEC isolate obtained from this slaughter house was from the hide sample. The beef produced from this organised slaughter house was found to be negative for EHEC and this may be due to the presence of overhead rail system and hygienic practices followed during the slaughter operations.

The slaughter house No. 4, where the maximum occurrence of EHEC was found, the slaughter of cattle was not there. They were importing carcasses from other states and cut into pieces in this facility. The high level of beef contamination in this slaughter house was found to be significantly different $(p<0.05)$ from all other sources of contamination. The critical points in this slaughter house were operator hands, knives, beef carcass, beef processing surfaces and water. The contamination of beef carcass may be due to the unhygienic slaughter operations and transportation to the slaughter house. The high level of EHEC recovery from beef may be due to the bacterial multiplication on beef which is rich in nutrients, by the time it reaches the slaughter house. Samples of tap water were taken from different sites of the same slaughter house, but only one sample was found positive for EHEC, which nullifies the chance of common source contamination. The contamination of water source may be due to the lodging of EHEC biofilms in the pipeline of water supply to that area. In SH4 the point of entry of beef carcass to the slaughter house and washing of carcass can be 
considered as the CCP1 and CCP2 will be the deboning stage.

Combining the results from all the four slaughter houses, the sources of contamination for EHEC in beef were found to be the dung and hide of the animal, operator hands, knife, beef carcass, beef contact surfaces and water (Fig. 3). On statistical analysis the occurrence in beef was found to be significantly different $(p<0.05)$ from all other sources of contamination. Between different sources of contamination there was no significant difference $(p<0.05)$ in the occurrence of EHEC. So it can be concluded that all the contaminating sources contributed equally to the occurrence of EHEC in beef. From the results obtained, the critical control pints of EHEC can be divided into two i.e., CCP1 and CCP2 (Fig. 4). Critical control point 1 is the point where a control measure can completely eliminate the EHEC from beef whereas CCP2 is the point where only partial control can be achieved over EHEC. The CCP1 of EHEC in beef processing line can be concluded as the dehiding, evisceration and washing stage of the carcass. The provision of an overhead rail system, hygienic precautions, and separation of clean and dirty area, washing hands and knife before entering clean area, use of chlorinated water for washing and regular monitoring of pipelines for biofilm lodging at CCP1 can prevent pathogen from the final product. Bleeding and deboning stage can be considered as the $\mathrm{CCP} 2$, where dung of the animal and beef contact surfaces was the major source of contamination. Only thing which can be done at this point is to minimise the spread of contamination from dung to other sources prevailing in the slaughter house and prevent the flow of blood on the floor by collecting blood to a separate vessel. This will make cleaning operation easy and reduce persistence of EHEC in slaughter environment. A wide range of disinfectants are effective against EHEC (Taylor et al.,
1999; Rutala et al., 2000). So a pre-washing followed by chemical disinfection and washing with hot water may be an effective method for removing EHEC from floor, equipments and beef processing surfaces.

From the study it was clear that the slaughter house where an over-head rail system, separation of clean and dirty area and hygienic practices were prevailing, a low occurrence of EHEC was found. This necessitates the urgent need of certification of slaughter houses, establishment of HACCP principles from production to consumption stage, establishing hygienic meat practices and regular monitoring of EHEC in identified sources of beef production line which is essential to prevent the outbreaks of EHEC infection.

\section{References}

Barrow, G. I., and Feltham, R. K. A.1995. Cowan and Steel's Manual for the Identification of Medical Bacteria $\left(3^{\text {rd }}\right.$ Edn). Cambridge University Press, London.PP: 94-163

Benjamin, M. M., and Datta, A. R.1995. Acid tolerance of enterohemorrhagic Escherichia coli. Appl. Environ. Microbiol., 61: 1669-1672.

Bielaszewska, M., Idelevich, E. A., Zhang, W., Bauwens, A., Schaumburg, F., Mellmann, A., Peters, G., and Karch, H.2012. Effects of Antibiotics on Shiga Toxin 2 Production and Bacteriophage Induction by Epidemic Escherichia coli O104:H4 Strain. Antimicrob. Agents Chemother., 56: 3277-3282.

Chapman, P. A., Siddons, C. A., Wright, D. J., Norman, P., Fox, J., and Crick, E.1993. Cattle as a possible source of verocytotoxin-producing Escherichia coli O157 infections in man. Epidemiol. Infect., 111: 439-448.

Fujisawa, T., Sata, S., Aikawa, K., Takahashi, T., Yamai, S., and Shimada, T.2000. Modification of sorbitol Mac Conkey 
medium containing cefixime and tellurite for isolation of Escherichia coli $\mathrm{O} 157$ : $\mathrm{H} 7$ from radish sprouts. Appl. Environ. Microbiol., 66: 3117 - 3118.

Hood, S. K., and Zottola, E. A.1997. Adherence to stainless steel by foodborne microorganisms during growth in model food systems. Int. J. Food Microbiol., 37: 145-153.

Indian Standards IS: 1622. 1978. Method of sampling and test for microbiological examination of water used in industry. Indian standards institution. Manak Bhavan Zafar Marg New Delhi 110002.

Louie, M., De-azavedo, J., Clarke, R., Borcyzk, A., Lior, H., Richter, M., and Brunton, J.1994. Sequence heterogeneity of the eae $A$ gene and detection of verotoxin producing Escherichia coli using serotype specific primers. Epidemiol. Infect., 112: 449 - 461.

Meng, J., Feng, P., and Doyle, P.2001. Pathogenic Escherichia coli. In: Doyle, IP and Ito, K, (Eds.), Compendium of methods for the microbiological examination of foods. American Public Health Associaion, Washington. PP: 331 $-341$.

Rajil, M. A., Adekeyel, J. O., Kwaga, J. K. P., and Bale, J. O. O. 2003. In vitro and in vivo pathogenicity studies of Escherichia coli isolated from poultry in Nigeria. Israel J. Vet. Med., 58: 81-87.

Rutala, W. A., Barbee, S. L., Aguiar, N. C., Sobsey, M. D., and Weber, D. J.2000. Antimicrobial activity of home disinfectants and natural products against potential human pathogens. Infect. Control Hospital Epidemiol., 21: 33-38.

Snedecor, G. W., and Cochran, W. G.1994.
Statistical Methods ( $8^{\text {th }}$ Edn). The Iowa State University press, Ames, Iowa, USA.

Tarr, L. P., Neill, A. M., Clausen, R. C., Watkins, L. S., Christie, L. D., and Hickman, O. R.1990. Escherichia coli 0157:H7 and the Hemolytic Uremic Syndrome: Importance of Early Cultures in Establishing the Etiology. J. Infect. Dis., 162: 553-556.

Taylor, J. H., Rogers, S. J., and Holah, J. T.1999. A comparison of the bactericidal efficacy of 18 disinfectants used in the food industry against Escherichia coli O157:H7 and Pseudomonas aeruginosa at 10 and $20{ }^{\circ} \mathrm{C}$. J. Appl. Microbiol., 87: $718-725$.

Tuttle, J., Gomez, T., Doyle, M. P., Wells, J. G., Zhao, T., Tauxe R. V., and Griffin, P. M.1999. Lessons from a large outbreak of Escherichia coli O157[ratio]H7 infections: insights into the infectious dose and method of widespread contamination of hamburger patties. Epidemiol. Infect., 122: 185-192.

USDA. 2015. Livestock and Poultry: World Markets and Trade. http://apps.fas.usda.gov/psdonline/circula rs/livestock_poultry.pdf

Wang, G., Zhao, T., and Doyle, M. P.1996. Fate of Enterohemorrhagic Escherichia coli O157:H7 in bovine feces. Appl. Environ. Microbiol., 62: 2567-2570.

Wells, J. G., Davis, B. R., Wachsmuth, I. K., Riley, L. W., Remis, R. S., Sokolow, R., and Morris, G. K.1983. Laboratory investigation of hemorrhagic colitis outbreaks associated with a rare Escherichia coli serotype. J. Clin. Microbiol., 18: 512-520.

\section{How to cite this article:}

Anu P. Joseph, C. Latha, K. Vinodkumar, V.K. Vinod and Sathu, T. 2018. An Important Approach for Control of Enterohaemorrhagic Escherichia coli by Identification of Contaminating Sources in Beef Production Line. Int.J.Curr.Microbiol.App.Sci. 7(01): 19211929. doi: https://doi.org/10.20546/ijcmas.2018.701.231 